\title{
Exclusion from Social Relations in Later Life and the Role of Gender: A Heuristic Model ${ }^{1}$
}

\section{Marja Aartsen, Kieran Walsh, Feliciano Villar, Ariela Lowenstein, Ruth Katz, Sigal Pearl Naim, Andreas Motel-Klingebiel, Anna Wanka, Anna Urbaniak, Thomas Hansen, Lucie Vidovićová}

\begin{abstract}
Being socially connected is a universal human need, but a substantial number of older men and women are or become excluded from these connections in later life. Exclusion from social relations (ESR) is unwanted as it undermines people's ability to lead a healthy, active, and independent life. Policies to reduce this form of exclusion have been limited in effectiveness, due in part to a broader lack of knowledge about the dynamics of social exclusion in older ages and the intersection of social exclusion with gender constructions. To advance our understanding of ESR in later life, we develop a heuristic model based on theories and previous empirical studies. Considering the gendered constructing forces of ESR in older age that can potentially lead to loneliness and reduced health and wellbeing, the model identifies individual drivers, such as biopsychosocial conditions, personal standards and life-course transitions, and macro-level drivers, such as norms and welfare state provisions. This model can serve as a conceptual platform for further theoretical development and empirical study on the gendered construction of ESR in later life. While our focus is on drivers of ESR and its outcomes, potential reversed effects are also discussed.
\end{abstract}

Keywords: social exclusion, social relations, older age

Aartsen, Marja, Walsh, Kieran, Villar, Feliciano, Lowenstein, Ariela, Katz, Ruth, Naim, Sigal Pearl, Motel-Klingebiel, Andreas, Wanka, Anna, Urbaniak, Anna, Hansen, Thomas, Vidovićová, Lucie. 2021. Exclusion from Social Relations in Later Life and the Role of Gender: A Heuristic Model. Gender a výzkum / Gender and Research 22 (1): 16-35, http://dx.doi.org/10.13060/gav.2021.005.

\footnotetext{
${ }^{1}$ Acknowledgements: This study is funded by the GENDER-NET Plus ERANET COFUND project, which has received funding from the European Union's Horizon 2020 research and innovation programme under grant agreement no. 741874. The national teams were supported by the following grants: Austria (FWF 14210/GNP187), Czechia (TAČR ZÉTA TJ03000002), Ireland (GNP-187), Israel (MSTS 3-15667), Norway (NFR 299859), Spain (PCI2019-103627), Sweden (Vetenskapsrådet 2018-00929). The authors declare no conflict of interest.
} 
Social exclusion is a broad concept, and in the context of older men's and women's lives it can be understood as the process in which people are or become separated from mainstream society (Moffatt, Glasgow 2009). The term social exclusion originally referred to those in poverty and who were excluded economically as a result of being unprotected by social insurance (e.g. homeless people, refugee and migrant populations). Despite research perspectives emphasising the multidimensionality of the phenomenon and incorporating material, social, civic, socio-cultural, and neighbourhood and community factors (e.g., Levitas, Pantazis, Fahmy, Gordon, Lloyd-Reichling, Patsios 2007; Walsh, Scharf, Keating 2017; Van Regenmortel, De Donder, Smetcoren, Lambotte, De Witte, Verté 2018; Dahlberg, McKee, Fritzell, Heap, Lennartson 2020), this narrow economic focus is still visible in present-day understandings within European policy. The European Commission, for example, defines social exclusion as being at risk of poverty, severe material deprivation, and/or living in households with very low work intensity (Eurostat 2015). Increasing attention, however, especially with respect to later-life experiences, is being directed at the social relational elements of the construct (Bak 2018) and the capacity of exclusion from social relations (ESR) to create a significant social disadvantage for heterogeneous populations of older men and women. Not many studies have given comprehensive and multifaceted consideration to ESR in older age, but there are some notable exceptions. In a critical review of the literature, Burholt et al. (2020) described ESR as an unwanted situation for both individuals and society, leading to lower levels of physical and mental health and lower levels of well-being, increased societal costs, and reduced social cohesion. It is the broader concept of social exclusion, and its manifestation in and its influence on the lives of older men and women, that is the focus of this article.

Despite the valuable contributions of some recent work (Van Regenmortel et al. 2021; Precupetu, Aartsen, Vasile 2019; Burholt et al. 2020), a major gap in the literature on ESR has been the limited attention devoted to the gendered construction of ESR and the influence of the gendered construction of ESR in older age. How the combined influence of individual (e.g. biopsychosocial conditions, life-course transitions) and macro socio-economic drivers (e.g. welfare state provisions; normative practices and values) operate through ESR to generate gender differences in loneliness, health, and wellbeing is also poorly understood. While some women can potentially possess all the major risk factors for ESR (e.g., being widowed, in poor health, with low income), there has been limited theoretical discussion of gender as an individual-level characteristic and as a constructed social position in experiences of this form of disadvantage. Gender differences can often be more pronounced in older age, where the combined negative effects of being old and being female on social exclusion is greater than being old or female alone. This indicates a potential double jeopardy for 
older women (Chappell, Havens 1980; Wenger, Davies, Shahtahmasebi, Scott 1996; Bradshaw, Kemp, Baldwin, Rowe 2004; Viruell-Fuentes, Miranda, Abdulrahim 2012; Kieny, Flores, Maurer, 2020). Nevertheless, as the construction and consequences of ESR may be different for heterogeneous groups of people, as well as across different societies (Crenshaw 1991), not all older women face significant risks of exclusion, and some older men can be particularly vulnerable to social disconnection. There are complex orders of advantage and disadvantage, oppression, and discrimination, which can bolster the role of gender in ESR based on the location of different individuals and groups at the intersection of age, ethnicity, sexual orientation, and economic background.

The aim of this paper marks an initial effort to further develop the framework presented by Burholt et al. (2020) into a heuristic model that explicates the gendered pathways of ESR, and the outcomes for loneliness, health, and wellbeing in later life. Based on theory and previous empirical research, we will examine how individualand macro-level drivers may create gender differences in ESR and use this model to emphasise factors that need to be considered when studying gendered aspects of ESR in later life. Our model also utilises aspects of the social convoy model of social relations (cf. Antonucci, Ajrouch, Birditt 2013; Fuller, Ajrouch, Antonucci 2020). The convoy model is a framework for understanding the determinants and outcomes of supportive intimate relationships, called the 'social convoy', that surround individuals and develop with them throughout their life course. People move in and out of the social network over the life course, and those who are the least close can become intimates as people age. Our model differs from the convoy model in the sense that it focuses not only on intimate social relations but on the three 'spheres of sociability' (Gallie, Paugam, Jacobs 2003): the household, the social network, and the wider society. Since we are interested in how drivers can contribute to the creation of ESR outcomes, and not vice versa, we do not focus on potential circular and reinforcing inter-relationships, where health and wellbeing can also serve as drivers of ESR, leading to changes in an individual's conditions and transitions. Like the social convoy model (Antonucci et al. 2013), in our model we also apply a life-course perspective (Elder 1994), where we consider conditions, opportunities, and decisions in earlier life phases to be important factors for ESR, with their impact and influence depending on historical and contextual positioning and origins in time and place. Life transitions, such as moving from wife to widow or from worker to retiree, are an important aspect of this perspective and can be accompanied by a shrinkage/change in family and social networks, contributing to a higher risk of social disadvantage (Yang, Victor 2011). We also acknowledge that people's current levels of ESR can be partly dependent on developments in other people's lives, exposing the influence and relevance of 'linkedlives' in the life-course analysis of social relations and resources. 
We begin by presenting the development of our definition of ESR in later life. Next, we describe potential individual- and macro-level drivers of ESR for older populations, followed by a discussion of theories on the intersection of these drivers with gender. We then present some methodological issues that may arise when measuring ESR. We conclude by presenting our heuristic model and a short discussion of the challenges involved in inferring and assessing causal relationships within this topic.

\section{Towards a definition of exclusion from social relations}

In using the term social relations, we refer to both interpersonal intimate connections with other individuals, and more general social relationships in the wider society that are valued by an older person. While all relationships may be important, social relations can have varying degrees of intimacy (e.g. partner, child, friend, neighbour, club members). A person's collection of social relations can vary in structure (size, composition, or frequency of contact) and function (e.g. support provision, stress buffering, socialising). Following Gallie et al. (2003), we include three domains of social relations: the household, the social network, and the wider society. The household consists of relations that are generally the closest, in physical and emotional terms (e.g. a partner, children, siblings), with people whom a person typically feels the need to belong to and connect with. Household relations can often provide the vast majority of support in times of crises because of their level of intimacy and proximity. The social network refers to the collection of people from outside the household, with whom a person also feels closely connected and maintains interpersonal relations and from whom a person may receive support. Wider society is used here to incorporate the contacts and exchanges that, while they may be the least close, are still important for providing valuable opportunities to connect with mainstream society, such as through voluntary work or political participation.

Across these three spheres, we consider ESR for older men and women as an objective (e.g. number of relations), subjective (e.g. perceived quality), and continuous multidimensional concept. We focus on its continuous nature, as a person is not included or excluded in a binary form, but rather can be excluded from one or more dimensions to various degrees. The multidimensional construction of ESR is considered as it incorporates/implicates the relationships, networks, supports, and opportunities that the three relational spheres represent. On this basis, we define ESR for older men and women as a situation in which people are socially and emotionally disconnected from adequate levels of intimate relationships, social networks, social support, andl or social opportunities. 


\section{Drivers of ESR}

In our discussion of drivers of ESR, we argue that ESR in later life arises from the direct effects on the individual and macro level, as well as from the intersection of processes and outcomes on these two levels. The function of this section is to provide a very brief overview of both sets of drivers. While their intersection with gender is highlighted where appropriate, this is primarily dealt with in a subsequent section.

\section{Individual drivers}

Individual aspects that we consider relevant for ESR and its outcomes are conditions, relationship standards, and life-course transitions. With conditions, we refer to the biopsychosocial conditions of an individual that shape their engagement with other people, such as gender, sexual orientation, income, socio-economic status, migration, and physical, mental, and cognitive health (Burholt et al. 2020). While women tend to have more kinship relations in the network than men (McPherson, Smith-Lovin, Brashears 2006), they are also more often widowed because of their longer life expectancy. Older lesbian, gay, bisexual, and transgender (LGBT) adults more often live alone and are less likely to have children compared to people with a heterosexual orientation (Yang, Victor 2018). They are also considered to be more often excluded as a result of the prejudicial attitudes of other people and service providers (ibidem). Poor mental and physical health impairs a person's ability to maintain their preferred level of social interaction (Bertoni, Celidoni, Weber 2015; Coyle, Dugan 2017; Croda 2015). While an increased need for support may mobilise helpers (Van Tilburg 1998), it can also lead to a reduction of helpers if the increased need arises from cognitive deterioration (Aartsen, Van Tilburg, Smits, Knipscheer 2004). A low socioeconomic status has been linked to having a lower-quality network (in terms of intimacy and providing support), which in turn leads to poor health (Aartsen, Veenstra, Hansen 2017). Low income, material deprivation, and poverty further limit participation in the wider community and compromise a person's ability to optimise their social network (Ajrouch, Blandon, Antonucci 2005). Relationship standards refer to the expectations that people have with respect to the level and nature of engagement with their network members. Relationship standards can act as motivators to maintain or enhance the quality and quantity of social relations people have, and those with high standards may work to replace social relations with new ones if they are lost. High standards may also induce loneliness if they are unrealistic, or simply not achievable given other personal, social, and economic parameters (De Jong Gierveld, Van Tilburg, Dykstra 2016). Major transitions in life, such as retirement, widowhood, divorce, or other forms of partnership dissolution, can function to shrink a person's social network if the lost relationships 
are not replaced by others (Bekhet, Zauszniewski 2012; Dahlberg, Andersson, McKee, Lennartsson 2015; Van Tilburg, Aartsen, Van der Pas 2015). Finally, migration within a country or across national boundaries can have a profoundly negative effect on social relations, as people who migrate are cut off from their primary contacts (Ajrouch et al. 2005; De Jong Gierveld, Van der Pas, Keating 2015).

\section{Macro-level drivers}

With macro-level drivers, we refer to the forces at the local and societal level that construct or influence ESR, such as neighbourhood qualities, norms and values, population turnover, and welfare state provisions. Aspects of the neighbourhood that are relevant to ESR include social, cultural, and health facilities within the locality and the walkability of the streets or the community, all of which can mediate social contact and the formation of social networks (Buffel, Phillipson, Scharf 2013; Walsh, O'Shea, Scharf 2019). Deprived neighbourhoods can possess higher crime rates, which increases the risk of victimisation for older people, and decreases personal mobility and socialisation within local settings (Scharf, Phillipson, Smith 2005). A sense of safety, which is not the same as objective measures of crime, can be related to a sense of belonging and place-based identity, which are important for fostering social interaction within the locality (Acierno, Rheinold, Resnick, Kilpatrick 2004). In countries where the norm is to be married and to rely on family when in need of support, people often have larger networks than those in individualistic countries, where people are more often alone (Yang, Victor 2011; Fokkema, De Jong Gierveld, Dykstra 2012; Sundström, Fransson, Malmberg, Davey 2009). Large-scale population turnover (such as that driven by immigration) at both the country-level and neighbourhood-level can reduce social cohesion, which undermines trust, reciprocity, and collective forms of socialisation, and that in turn increases the risk of ESR (Kearns, Bailey, Gannon, Livingston, Leyland 2014). Evidence also suggests that welfare state provisions can directly impact integration. For example, a study conducted in Israel found that well-developed and adequate services, facilitated by local associations, enabled older people to become more involved in the community and to experience a greater level of integration in society (Brick, lekovitch, Naim 2018). Hence, macrolevel drivers may impact all three levels of ESR: the household, the social network, and the wider society.

\section{Interrelations between individual and macro-level drivers of ESR}

The impact that individual drivers have on ESR may not be independent from macrolevel drivers, and the risk of being socially excluded differs across European countries (Tsakloglou, Papadopoulos 2002). Strong social policies typical for social democratic 


\section{STATI / ARTICLES}

welfare regimes may lower the negative impact of individual factors through processes of decommodification and defamilialisation. Decommodification is the degree to which an individual or family can uphold a socially acceptable standard of living independent of labour-market participation (Esping-Andersen 1999). Defamilialisation refers to actions taken by the state to support professional care services for the purpose of facilitating greater participation of women in the work force, such as universal or subsidised childcare services and welfare support for part-time work (Mandel, Shalev 2009). It is therefore important to consider the macro-social context when analysing drivers and outcomes of ESR.

Relational standards, previously discussed as motivators for social interaction, can be shaped by culturally defined gender norms linked to being alone and/or the provision of care and support. While people in southern collectivistic countries expect help from their family and friends when they are in need of care, people in individualistic Nordic countries have lower expectations as they can rely on professional organisations for their support (Jylhä, Jokela 1990). Therefore, people who are a little more isolated with a little less support may be more likely to experience feelings of loneliness in collectivistic countries. This is supported by a growing number of cross-national studies that have observed that despite the higher number of people who are alone in the northwest of Europe, the prevalence of loneliness is lower than in the southeast of Europe (Jylhä, Jokela 1990; Yang, Victor 2011; Fokkema, De Jong Gierveld, Dykstra 2012; Hansen, Slagsvold 2016; Sundström, Fransson, Malmberg, Davey 2009). Welfare state provisions, such as professional health care or social services, may compensate for the absence of social relations that are important for the individual (Broese van Groenou, De Boer 2016), which may lead to a weakened association between ESR, on the one hand, and loneliness health, and wellbeing, on the other.

The life-course perspective (Elder, 1994) provides a framework with which to understand how and why individual and macro-level drivers of ESR interact. Applied to exclusionary processes, it emphasises how an individual's current level of ESR can be shaped by earlier conditions, opportunities, and decisions during their lives. It is also shaped by historical and temporal and geographical/spatial context as the choices people make in life are bounded by circumstances, such as those regulating genderbased expectations, roles, and institutional support, which vary across time, place, and social group. As noted by Dewilde (2003), individual differences in education levels are shaped by the family in which people are born including the household expectations regarding male and female children, and the opportunity structures provided by the welfare system to access education. This affects the ability of men and women to accumulate financial and social resources over the life course and the various ways in which social groups rewards the decisions of individuals. 


\section{Exclusion from social relations and the impact on loneliness, health, and wellbeing}

Although ESR and loneliness are highly correlated, they are not the same. Some people can feel lonely even if they are objectively well-embedded in a social network, and not all people who are excluded from social relations do feel lonely (De Jong Gierveld et al. 2016). Loneliness is a perceived state and arises when there is an unacceptable discrepancy between the quality and quantity of the social relations that an older man or woman has and what they would like to have (Perlman, Peplau 1982). In line with the Burholt et al. (2020) framework and the cognitive approach to loneliness developed by Perlman and Peplau (1982), we consider loneliness an outcome of ESR. Both ESR and loneliness can lead to adverse health and wellbeing outcomes.

The extent to which health outcomes should be attributed to ESR, to loneliness, or to both in a linear process of construction is not always clear (Steptoe et al. 2013). Some studies associate ESR with an increased mortality risk that is comparable to long-standing risk behaviours, such as smoking, obesity, or lack of physical activity (Alcaraz et al. 2019; Holt-Lunstad, Smith, Layton 2010), with similar effects being observed for loneliness (Luo et al. 2012). ESR was also found to be related to an increase in general health problems in older age, such as higher blood pressure and coronary disease (Thurston, Kubzansky 2009; Tomaka, Thompson, Palacios 2006), and a decline in cognitive function (Shankar, Rafnsson, Steptoe 2015). Older people who are experiencing loneliness tend to have more physical-health consultations with a doctor (Gerst-Emerson, Jayawardhana 2015), and their self-rated health is typically significantly worse than people who are not experiencing loneliness (Coyle, Dugan 2012).

ESR and loneliness are also associated with a number of wellbeing aspects. Higher levels of loneliness are associated with poorer life satisfaction (Bai, Yan, Knapp 2018), lower self-esteem, mistrust, and a lack of self-confidence (Masi et al. 2011), and with higher levels of anger, anxiety, pessimism, and depression (Cacioppo et al. 2006). Longitudinal studies on loneliness point to how mental health outcomes of loneliness in older age might be greater than in other life stages (e.g. Dykstra et al. 2005; Victor, Bowling 2012). In line with the cumulative advantage/disadvantage theory (Dannefer 2003), this can be interpreted as an accumulation of disadvantages, as the oldest old people experience the greatest cumulative exposure. In sum, there is solid evidence that ESR leads to increased loneliness, and ESR and loneliness may have independent and combined negative effects on health and wellbeing. 


\section{The role of gender}

Up to this point, we have only referenced gender differences, as they pertain in a cursory way to drivers and outcomes. In this section, we focus on the specific role that gender can play in relation to ESR. With gender, we refer to the roles and responsibilities of people as constructed by families, societies, and cultures, which are generally distinct for men and women. A social role can be seen as a set of social relations between a person and a social circle involving negotiated duties obligations, rights, and privileges (Lopata 2006). Microstructural perspectives on gender inequalities have emphasised the importance of social roles and socialisation in constructing gender differences. Based on differences in socialisation (Stockard 2006), gendered social roles in the private and public sphere have different opportunities to create or maintain relations in the three spheres of sociability. As men most often occupy roles in the public sphere and women roles in the private sphere of the household (Lopata 2006), the prescribed social roles may lead to gender inequalities in ESR and loneliness. For example, women are typically the primary caregivers for children in married or partnered households, and it is also often women who have children in their care after a divorce (McLanahan, Kelly 2006). These responsibilities limit the possibilities women have for paid employment outside the home, which can potentially lead to an accumulation of disadvantages and increased gender inequalities with respect to the different facets of economic and social participation (Dunn, Skaggs 2006). As a consequence, older women are more likely to be excluded from social relations and more likely to be lonely. However, it is also observed that divorce in midlife leads to a higher increase in loneliness among men, compared to women, which can sometimes be due to women possessing alternative sources of support (Dykstra, Fokkema 2007).

Gender theories that emphasise a macro-structural perspective may further help to illuminate gender inequalities in ESR. A relevant example that uses this perspective is the feminisation of poverty, and poverty increases the risk of ESR and loneliness (Scharf, Phillipson, Smith 2005). There are various explanations for this, including changing family structures (e.g. first marriages occurring at a later age and an increase in divorce rates) and the meagre welfare benefits that certain groups of women sometimes receive, including various kinds of carer allowances (McLanahan, Kelly 2006). Moreover, older women tend to have lower levels of education and this has ramifications for a range of different exclusionary outcomes throughout the life course. This includes earning not only less than their male counterparts, but often experiencing more disrupted working careers because of their role in family care. As a result, older women are likely to receive lower pensions and consequently encounter higher risks of poverty (Eurostat 2015). An increasing proportion of single people, therefore, have to rely on their own economic resources, and these resources are generally lower for women than for men. Gender 
thus creates the basis for women to end up in a more disadvantaged position than men, and although differences between men and women may not be that clear-cut, it is a cross-cutting and overarching factor in our model.

\section{Theoretical perspectives on ESR-changes over time}

While we discussed ESR mainly as a static situation of exclusion, we acknowledge its dynamic nature, as people can move in and out of a situation in which they are excluded from social relations (Burholt et al. 2020; Antonucci et al. 2013). Individual transitions and changes in resources affect a person's risk of being excluded, and experiencing one form of exclusion can raise the odds of experiencing exclusion in other domains (Walsh et al. 2017). Events in society such as the housing crisis in 2008 have increased the number of homeless and poor people, and homelessness and poverty can in turn make it more difficult to maintain and improve social relations, at least during a crisis. The social distancing that was introduced to reduce the spread of the Coronavirus in $\mathbf{2 0 2 0}$ has also resulted - hopefully temporarily - in the exclusion of people from their social networks and has reduced their opportunities to participate in the wider society. The fact that ESR can change over time is relevant for our theoretical understanding, it is also important that empirical research acknowledge that the state of ESR can change over the life course.

A number of theories can be helpful in order to better understand ESR changes. The Socio-emotional Selectivity Theory (SST) developed by Carstensen (1992) understands changes in the composition of a social network as a consequence of changing motivations for particular types of social relations. SST is based on the notion that it is not age but rather people's perceived time horizon that determines their motivation to choose certain types of relations. As long as an individual's time horizon is perceived as open-ended, knowledge-related goals are prioritised. When time is perceived to be limited, emotional goals become more important. Consequently, when life unfolds and people become older, their preference for social relations change from relations that provide knowledge to social relations that provide intimacy and emotional support. This is likely to be true for men and women, albeit to different degrees.

A scholarly debate in family research that is relevant for changes in household relations has centred on the conceptualisation of intergenerational relationships and the solidarity-conflict ambivalence model (Lowenstein 2007; Katz et al. 2005). The premise of the solidarity-conflict model is that levels of cohesion and conflict predict parent-child relations and their outcomes in later life. The ambivalence model states that adult intergenerational relations revolve around sociological and psychological contradictions. This is important because of the profound increase in average life expectancy, meaning that more people spend more years within family 


\section{STATI / ARTICLES}

structures, while these structures are constantly changing. Moreover, population ageing and globalisation have increased the diversity and complexity of family lives and intergenerational bonds.

\section{Methodological considerations in the assessment of ESR}

Before presenting our heuristic model, we address some methodological considerations related to the key concept of ESR. In our approach to ESR, we distinguish between three different levels of social relations: the household, the social network, and wider society. Being excluded from household relations implies a situation in which a person may live without a partner and/or children in the same household. This includes people who are divorced or widowed but not remarried, as well as people who never married or have a partner outside the household. Measuring the social network entails assessing the network in terms of both quality and quantity. While a large network may potentially have more support capacity than a small network, this is not necessarily true. Relevant aspects of the social network with respect to ESR include the structure of the network (e.g. number of people in the network, contact frequency, and the composition of the network) and its function (e.g. support provision, the quality of social relations, network satisfaction). There is a dynamic interplay between network size and the amount of support provided by the social network, as network members may be less ready to provide support if the network is large and other people are available to provide support (Tolkacheva et al. 2011). Therefore, a number of scholars have argued that a network typology that combines the structural and functional aspects of the social network is necessary when studying the construction and outcomes of the social network (Wenger 1991; Litwin, Shiovitz-Ezra 2006; Cheng et al. 2009). There are several approaches to defining network type, one of the first of which was the qualitative approach by Wenger (1991), which was based on interviews with older people living in Wales (UK). Inspired by these ideas, quantitative studies have attempted to develop a network typology, often based on a person-centred approach. The goal of a person-centred approach - as opposed to variable-centred approaches - is to group people in smaller homogeneous subgroups of individuals who have the same structural and functional characteristics of their social network, which is different from other subgroups (Muthén, Muthén 2000). A helpful method for defining network types in a dataset is Latent Class Analysis (McCutcheon 1987), which empirically identifies groups of people with the same social network type based on a number of observed variables that are indicative of the quality (support exchange, network satisfaction) and the quantity (network size, composition, contact frequency) of the social network. This method of creating network typologies was applied in previous studies (e.g., Aartsen et al. 2004; Ellwardt et al. 2017; Litwin 2001; Mikulionienè, Gaižaukaitè, Morkevičius 2021). Social connections 
with people in the wider society include a variety of relations that are more distant but are still important to the individual and are with individuals with whom they are in regular contact. Voluntary work, participation in social, leisure, or political activities, or providing help to people outside the household or social network are examples of social opportunities that connect people to others with whom they are the least close and connect them to mainstream society.

\section{Towards a heuristic model of gendered ESR}

Our heuristic model of ESR builds on the critical review of Burholt et al. (2020) and the social convoy model (Antonucci et al. 2013) and emphasises gender as a cross-cutting and overarching factor that influences experiences of ESR in later life. We defined ESR as a situation in which people are socially and emotionally disconnected from adequate levels of intimate relationships, social networks, social support, and/or social opportunities. We incorporated relevant aspects of feminist theory, understandings of social exclusion in later life, socio-emotional selectivity theory, and the conceptual interrelationship between solidarity, conflict, and ambivalence. We further argued that ESR is driven by individual and macro-level factors and the interaction between the two. We also discussed that ESR leads to increased feelings of loneliness and diminished health and wellbeing and that individual and macro-level drivers may modify the strength of these impacts. The heuristic model is depicted in Figure 1.

Figure 1: Heuristic model for the causes and consequences of exclusion from social relations

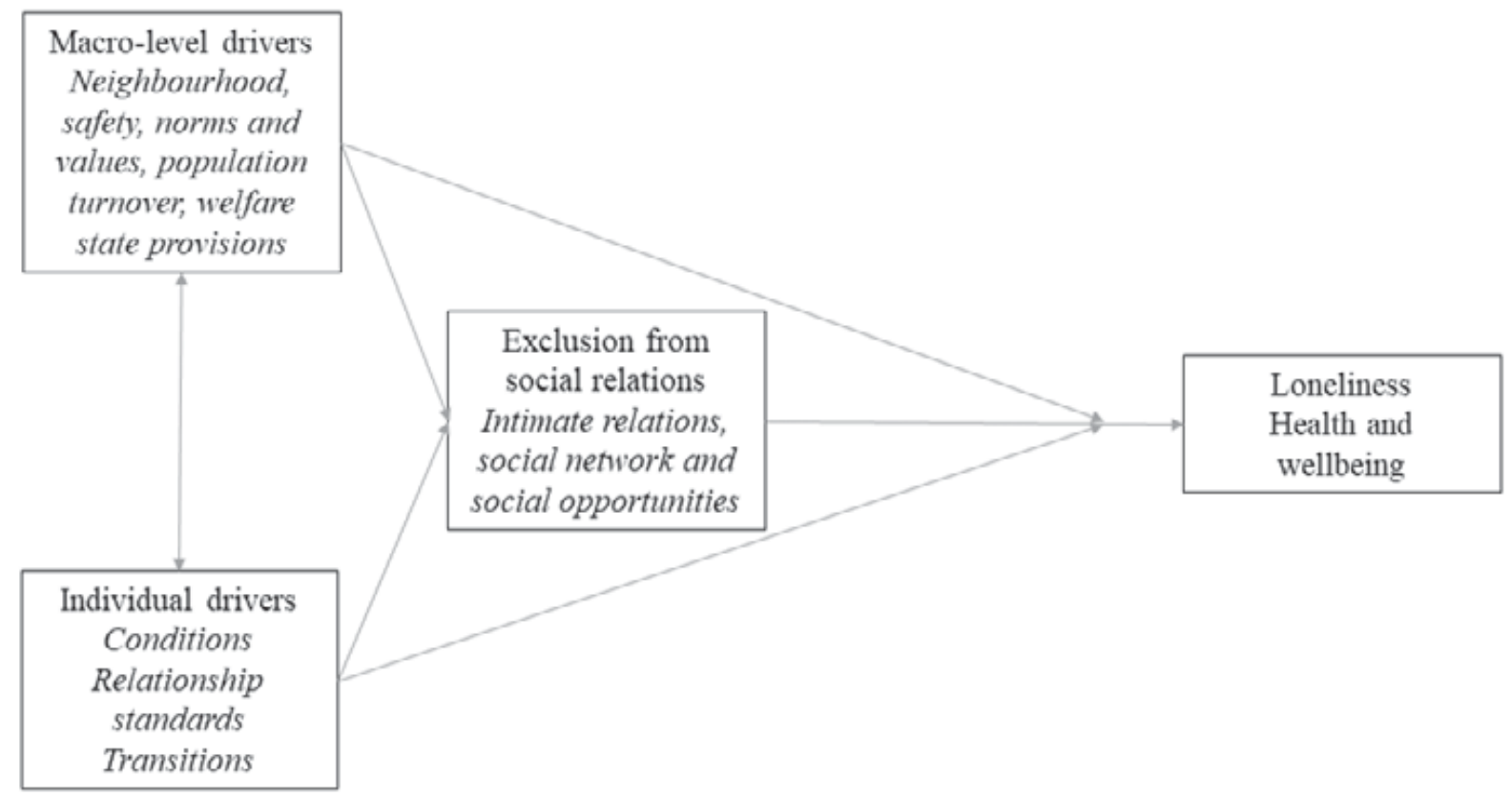


Although we present the model mainly in terms of drivers of ESR and its outcomes, the model does not exclude feedback loops and reversed causation. For example, the health and wellbeing outcomes in our model may in turn lead to ESR, which was also acknowledged when discussing the individual drivers of ESR. In addition, it is argued that loneliness can also motivate people to reconnect or maintain social relations in the same way that hunger and thirst motivate people to feed the body (Hawkley, Cacioppo 2010). When analysing and interpreting the heuristic model, scholars should take into account potential reversed effects.

To conclude, the heuristic model may provide a useful framework for analysing the origins of gender differences in the prevalence and generation of ESR across European countries and for identifying the consequences of this exclusion for health and wellbeing. A next step would be to validate the model, and to do this crossnational and longitudinal studies are needed. Findings from such studies would be highly relevant for the scientific debate about gender inequalities in ESR and would help inform policies for the reduction of the levels of exclusion from social relations amongst older men and women.

\section{References}

Aartsen, M. J., T. Van Tilburg, C. H. Smits, K. C. Knipscheer. 2004. A Longitudinal Study of the Impact of Physical and Cognitive Decline on the Personal Network in Old Age. Journal of Social and Personal Relationships 21 (2): 249-266, https://doi. org/10.1177/0265407504041386.

Aartsen, M., M. Veenstra, T. Hansen. 2017. Social Pathways to Health: On the Mediating Role of the Social Network in the Relation between Socio-Economic Position and Health. Social Science and Medicine - Population Health 3: 419-426, https://doi.org/10.1016/j. ssmph.2017.05.006.

Acierno, R., A. A. Rheingold, H. S. Resnick, D. G. Kilpatrick. 2004. Predictors of Fear of Crime in Older Adults. Journal of Anxiety Disorders 18 (3): 385-396, https://doi. org/10.1016/S0887-6185(03)00012-4.

Ajrouch, K. J., A. Y. Blandon, T. C. Antonucci. 2005. Social Networks among Men and Women: The Effects of Age and Socioeconomic Status. The Journals of Gerontology Series B: Psychological Sciences and Social Sciences 60 (6): S311-S317, https://doi. org/10.1093/geronb/60.6.5311.

Alcaraz, K. I., K. S. Eddens, J. L. Blase, W. R. Diver, A. V. Patel, L. R. Teras, et al. 2019. Social Isolation and Mortality in US Black and White Men and Women. American Journal of Epidemiology 188 (1): 102-109, https://doi.org/10.1093/aje/kwy231.

Antonucci, T. C., K. J. Ajrouch, K. S. Birditt. 2013. The Convoy Model: Explaining Social Relations from a Multidisciplinary Perspective. The Gerontologist 54 (1): 82-92, http:// dx.doi.org/10.1093/geront/gnt118.

Bai, X., S. Yang, M. Knapp. 2018. Sources and Directions of Social Support and Life 
Satisfaction among Solitary Chinese Older Adults in Hong Kong: The Mediating Role of Sense of Loneliness. Clinical Interventions in Aging 13: 63. https://dx.doi. org/10.2147\%2FCIA.S148334.

Bak, C. K. 2018. Definitions and Measurement of Social Exclusion - A Conceptual and Methodological Review. Advances in Applied Sociology 8 (5): 422-433, http://dx.doi. org/10.4236/aasoci.2018.85025.

Bekhet, A. K., J. A. Zauszniewski. 2012. Mental Health of Elders in Retirement Communities: Is Loneliness a Key Factor? Archives of Psychiatric Nursing 26 (3): 214-224, http://dx.doi.org/10.1016/j.apnu.2011.09.007.

Bertoni, M, M. Celidoni, G. Weber. 2015. Does Hearing Impairment Lead to Social Exclusion? Pp 93-102 in Börsch-Supan A, T. Kneip, H. Litwin, M. Myck, G. Weber (eds.). Ageing in Europe - Supporting Policies for an Inclusive Society. Berlin: De Gruyter, https:// doi.org/10.1515/9783110444414-010.

Bradshaw, J., P. Kemp, S. Baldwin, A. Rowe. 2004. The Drivers of Social Exclusion. A review of the literature. Report written for the Social Exclusion Unit in the Breaking the Cycle Series. London: Social Exclusion Unit, University of York.

Brick, Y., E. lekovitch, S. P. Naim. 2018. Local Associations for the Elderly in Israel Contribution for the Elders [in Hebrew]. Gerontology and Geriatrics, 45 (1): 71-92.

Broese Van Groenou, M. I. B., A. De Boer. 2016. Providing Informal Care in A Changing Society. European Journal of Ageing 13 (3): 271-279, http://dx.doi.org/10.1007/s10433016-0370-7.

Buffel, T., C. Phillipson, T. Scharf. 2013. Experiences of Neighbourhood Exclusion and Inclusion Among Older People Living in Deprived Inner-City Areas in Belgium and England. Ageing \& Society 33 (1): 89-109, https://doi.org/10.1017/S0144686X12000542.

Burholt, V., B. Winter, M. Aartsen, C. Constantinou, L. Dahlberg, V. Feliciano, J. de Jong Gierveld, S. van Regenmortel, C. Waldegrave. 2020. A Critical Review and Development of a Conceptual Model of Exclusion from Social Relations for Older People. European Journal of Ageing 17 (1): 3-19, http://dx.doi.org/10.1007/s10433-019-00506-0.

Cacioppo, J. T., L. C. Hawkley, J. M. Ernst, M. Burleson, G. G. Berntson, B. Nouriani, D. Spiegel. 2006. Loneliness Within a Nomological Net: An Evolutionary Perspective. Journal of Research on Personality 40 (6): 1054-1085, https://doi.org/10.1016/j.jp.2005.11.007.

Carstensen, L. L. 1992. Social and Emotional Patterns in Adulthood: Support for Socioemotional Selectivity Theory. Psychology and Aging 7 (3): 331-338, http://dx.doi. org/10.1037/0882-7974.7.3.331.

Chappell, N. L., B. Havens. 1980. Old and Female: Testing the Double Jeopardy Hypothesis. Sociological Quarterly 21 (2): 157-171.

Cheng, S. T., C. K. Lee, A. C. Chan, E. M. Leung, J. J. Lee. 2009. Social Network Types and Subjective Well-Being in Chinese Older Adults. Journals of Gerontology Series B: Psychological Sciences and Social Sciences 64 (6): 713-722, https://doi.org/10.1093/ geronb/gbp075.

Coyle, C. E., E. Dugan. 2012. Social Isolation, Loneliness and Health among Older Adults. Journal of Aging and Health 24 (8): 1346-1363, http://dx.doi. org/10.1177/0898264312460275. 
Crenshaw, K. 1991. Demarginalizing the Intersection of Race and Sex: A Black Feminist Critique of Antidiscrimination Doctrine, Feminist theory, and Antiracist Politics. Pp. 57-80 in Bartlett K. T., R. Kennedy (eds.). Feminist Legal Theory, Readings in Law and Gender. New York: Routledge.

Croda, E. 2015. Pain and Social Exclusion among the European Older People. Pp 313320 in Börsch-Supan A., T. Kneip, H. Litwin, M. Myck, G. Weber (eds.). Ageing in Europe - Supporting Policies for an Inclusive Society. Berlin: De Gruyter, https://doi. org/10.1515/9783110444414-030.

Dahlberg, L., L. Andersson, K. J. Mckee, C. Lennartsson.2015. Predictors of Loneliness Among Older Women and Men in Sweden: A National Longitudinal Study.

Aging \& Mental Health 19 (5): 409-417, http://dx.doi.org/10.1080/13607863.2014.944091.

Dahlberg, L., K. J. McKee, J. Fritzell, J. Heap, C. Lennartsson. 2020. Trends and Gender Associations in Social Exclusion in Older Adults in Sweden Over Two Decades. Archives of Gerontology and Geriatrics 89 (July-August), https://doi.org/10.1016/j. archger.2020.104032.

Dannefer, D. 2003. Cumulative Advantage/Disadvantage and the Life Course: CrossFertilizing Age and Social Science Theory. The Journals of Gerontology Series B: Psychological Sciences and Social Sciences 58 (6): S327-S337, https://doi.org/10.1093/ geronb/58.6.S327.

De Jong Gierveld, J., S. Van Der Pas, N. Keating. 2015. Loneliness of Older Immigrant Groups in Canada: Effects of Ethnic-Cultural Background. Journal of Cross-Cultural Gerontology 30 (3): 251-268, http://dx.doi.org/10.1007/s10823-015-9265-x.

De Jong Gierveld, J., T. Van Tilburg, P. Dykstra. 2016. New Ways of Theorizing and Conducting Research in the Field of Loneliness and Social Isolation. Pp. 391-404 in Vangelisti, A. L., D. Perlman (eds.). Cambridge Handbook of Personal Relationships. 2nd ed. Cambridge, New York: Cambridge University Press.

Dewilde, C. 2003. A Life Course Perspective on Social Exclusion and Poverty. The British Journal of Sociology 54 (1): 109-128, http://dx.doi.org/10.1080/0007131032000045923.

Dunn, D., S. Skaggs. 2006. Gender and Paid Work in industrial Nations. Pp. 321-342 in Handbook of the Sociology of Gender. Boston, MA: Springer.

Dykstra, P. A., T. G. Van Tilburg, J. De Jong Gierveld. 2005. Changes in Older Adult Loneliness: Results from a Seven-Year Longitudinal Study. Research on Aging 27 (6): 725-747, https://doi.org/10.1177/0164027505279712.

Dykstra, P. A., T. Fokkema. 2007. Social and Emotional Loneliness Among Divorced and Married Men and Women: Comparing the Deficit and Cognitive Perspectives. Basic and Applied Social Psychology 29 (1): 1-12, https://doi.org/10.1080/01973530701330843.

Elder, Jr., G. H. 1994. Time, Human Agency, and Social Change: Perspectives on the Life Course. Social Psychology Quarterly, 4-15, https://doi.org/10.2307/2786971.

Ellwardt, L., M. Aartsen, T. Van Tilburg.2017. Types of Non-Kin Networks and Their Association with Survival in Late Adulthood: A Latent Class Approach. Journals of Gerontology Series B: Psychological Sciences and Social Sciences 72 (4): 694-705, http:// dx.doi.org/10.1093/geronb/gbw142. 
Esping-Andersen, G. 1999. The Social Foundations of Post-Industrial Economies. New York: Oxford University Press, http://dx.doi.org/10.1093/0198742002.001.0001.

Eurostat. 2015. People at Risk of Poverty or Social Exclusion. Statistics Explained. Retrieved 15 June 2018 (https://Ec.Europa.Eu/Eurostat/Statistics-Explained/index.Php?Title=People_ At_Risk_of_Poverty_Or_Social_Exclusion).

Fokkema, T., J. De Jong Gierveld, P. A. Dykstra. 2012. Cross-National Differences in Older Adult Loneliness. The Journal of Psychology 146 (1-2): 201-228, http://dx.doi.org/ 10.1080/00223980.2011.631612.

Fuller, H. R., K. J Ajrouch, T. C. Antonucci. 2020. The Convoy Model and Later Life Family Relationships. Journal of Family Theory \& Review 12 (2): 126-146, https://doi.org/10.1111/ jftr.12376.

Gallie, D., S. Paugam, S. Jacobs. 2003. Unemployment, Poverty and Social Isolation: Is There a Vicious Circle of Social Exclusion? European Societies 5 (1): 1-32, http://dx.doi.org/10.10 93/0199271844.003.0002.

Gerst-Emerson, K., J. Jayawardhana. 2015. Loneliness as a Public Health Issue: The Impact of Loneliness on Health Care Utilization Among Older Adults. American Journal of Public Health 105 (5): 1013-1019, http://dx.doi.org/10.2105/AJPH.2014.302427.

Hansen, T., B. Slagsvold. 2016. Late-Life Loneliness in 11 European Countries: Results from the Generations and Gender Survey. Social Indicators Research 129 (1): 445-464, http:// dx.doi.org/10.1007/S11205-015-1111-6.

Hawkley, L. C., J. T. Cacioppo. 2010. Loneliness Matters: A Theoretical and Empirical Review of Consequences and Mechanisms. Annals of Behavioral Medicine 40 (2): 218-227, http://dx.doi.org/10.1007/s12160-010-9210-8.

Holt-Lunstad, J., T. B. Smith, J. B. Layton. (2010). Social Relationships and Mortality Risk: A Meta-Analytic Review. PLoS Medicine 7 (7): e1000316, https://doi.org/10.1371/journal. pmed.1000316.

Jylhä, M., J. Jokela. 1990. Individual Experiences as Cultural - A Cross-Cultural Study on Loneliness Among the Elderly. Ageing \& Society 10 (3): 295-315, http://dx.doi.org/ https://doi.org/10.1017/S0144686X00008308.

Katz, R., A. Lowenstein, J. Phillips, S. O. Daatland. 2005. Theorizing Intergenerational Family Relations: Solidarity, Conflict and Ambivalence in Cross-National Contexts Pp. 393407 in Bengtson, V, A. C. Acock, K. R. Allen, P. Dilworth-Anderson, D. M. Klein (eds.). Sourcebook of Family Theory \& Research. Thousand Oaks, CA: Sage Publications, https:// dx.doi.org/10.4135/9781412990172.n16.

Kearns, A., N. Bailey, M. Gannon, M. Livingston, A. Leyland. 2014. 'All in it Together'? Social Cohesion in A Divided Society: Attitudes to Income Inequality and Redistribution in A Residential Context. Journal of Social Policy 43 (3): 453-477, https://doi.org/10.1017/ S0047279414000063.

Kieny, C., G. Flores, J. Maurer. 2020. Assessing and Decomposing Gender Differences in Evaluative and Emotional Well-Being among Older Adults in the Developing World. Review of Economics of the Household 19 (1): 189-221, http://dx.doi.org/10.1007/ s11150-020-09521-y.

Levitas, R., C. Pantazis, E. Fahmy, D. Gordon, E. Lloyd-Reichling, D. Patsios. 2007. The Multi- 
Dimensional Analysis of Social Exclusion. Bristol: University of Bristol.

Litwin, H. 2001. Social Network Type and Morale in Old Age. The Gerontologist 41 (4): 516-524, http://dx.doi.org/10.1093/geront/41.4.516.

Litwin, H., S. Shiovitz-Ezra. 2006. Network Type and Mortality Risk in Later Life. The Gerontologist 46 (6): 735-743, https://doi.org/10.1093/geront/46.6.735.

Lopata, H. Z. 2006. Gender and Social Roles. Pp. 229-246 in Handbook of the Sociology of Gender. Boston, MA: Springer.

Lowenstein, A. 2007. Solidarity-Conflict and Ambivalence: Testing Two Conceptual Frameworks and their Impact on Quality of Life for Older Family Members. The Journals of Gerontology Series B: Psychological Sciences and Social Sciences 62 (2): S100-S107, http://dx.doi.org/10.1093/geronb/62.2.s100.

Luo, Y., L. C. Hawkley, L. J. Waite, J. T. Cacioppo. 2012. Loneliness, Health, and Mortality in Old Age: A National Longitudinal Study. Social Science and Medicine 74 (6): 907-914, http://dx.doi.org/10.1016/j.socscimed.2011.11.028.

Mandel, H., M. Shalev. 2009. How Welfare States Shape the Gender Pay Gap: A Theoretical and Comparative Analysis. Social Forces 87 (4): 1873-1911, https://doi.org/10.1353/ sof.0.0187.

Masi, C. M., H. Y. Chen, L. C. Hawkley, J. T. Cacioppo. 2011. A Meta-Analysis of Interventions to Reduce Loneliness. Personality and Social Psychology Review 15 (3): 219-266, http://dx.doi.org/10.1177/1088868310377394.

McCutcheon, A. L. 1987. Latent Class Analysis. No. 64. Sage University Paper: Series Quantitative Applications in the Social Sciences. Newbury Park, London: Sage.

McLanahan, S. S., E. L. Kelly. 2006. The Feminization of Poverty. Pp. 127-145 in Handbook of the Sociology of Gender. Boston, MA: Springer.

McPherson, M., L. Smith-Lovin, M. E. Brashears. 2006. Social Isolation in America: Changes in Core Discussion Networks Over Two Decades. American Sociological Review 71 (3): 353-375, https://doi.org/10.1177/000312240607100301.

Mikulionienè, S., Gaižaukaitè, I., Morkevičius, V. 2021. Patterns of Social Embeddedness in Late Adulthood: Gender and Other Covariates. Gender a výzkum 22 (1), this issue.

Moffatt, S., N. Glasgow. 2009. How Useful Is the Concept of Social Exclusion When Applied to Rural Older People in the United Kingdom and the United States? Regional Studies 43 (10): 1291-1303, https://doi.org/10.1080/00343400903002697.

Muthén, L. K., B. O. Muthén. 1998-2015. Mplus User's Guide. Seventh Edition. Los Angeles, CA: Muthén \& Muthén.

Perlman, D., L. A. Peplau. 1982. Theoretical Approaches to Loneliness. Pp. 123-134 in Peplau, L. A., Perlman, D. (eds.). Loneliness: A Sourcebook of Current Theory, Research and Therapy. New York: Wiley.

Precupetu, I., M. Aartsen, M. Vasile. 2019. Social Exclusion and Mental Wellbeing in Older Romanians. Social Inclusion 7 (3): 4-16, http://dx.doi.org/10.17645/SI.V7I3.2008.

Scharf, T., C. Phillipson, A. E. Smith. 2005. Social Exclusion of Older People in Deprived Urban Communities of England. European Journal of Ageing 2 (2): 76-87, http://dx.doi. org/10.1007/s10433-005-0025-6.

Shankar, A., S. B. Rafnsson, A. Steptoe. 2015. Longitudinal Associations Between Social 
Connections and Subjective Wellbeing in the English Longitudinal Study of Ageing. Psychology \& Health 30 (6): 686-698, http://dx.doi.org/10.1080/08870446.2014.979823. Steptoe, A., A. Shankar, P. Demakakos, J. Wardle. 2013. Social Isolation, Loneliness, and All-Cause Mortality in Older Men and Women. Proceedings of the National Academy of Sciences 110 (15): 5797-5801, https://doi.org/10.1073/pnas.1219686110.

Stockard, J. 2006. Gender Socialization. Pp. 215-227 in Handbook of the Sociology of Gender. Boston, MA: Springer.

Sundström, G., E. Fransson, B. Malmberg, A. Davey. 2009. Loneliness among Older Europeans. European Journal of Ageing 6 (4): 267-275, http://dx.doi.org/10.1007/ s10433-009-0134-8.

Thurston, R. C., L. D. Kubzansky. 2009. Women, Loneliness, and Incident Coronary Heart Disease. Psychosomatic Medicine 71 (8): 836-842, http://dx.doi.org/ 10.1097/ PSY.0b013e3181b40efc.

Tolkacheva, N., M. Broese Van Groenou, A. De Boer, T. Van Tilburg. 2011. The Impact of Informal Care-Giving Networks on Adult Children's Caregiver Burden. Ageing \& Society 31 (1): 34-51, http://dx.doi.org/10.1017/S0144686X10000711.

Tomaka, J., S. Thompson, R. Palacios. 2006. The Relation of Social Isolation, Loneliness, and Social Support to Disease Outcomes among the Elderly. Journal of Aging and Health 18 (3): 359-384, http://dx.doi.org/10.1177/0898264305280993.

Tsakloglou, P., F. Papadopoulos. 2002. Aggregate Level and Determining Factors of Social Exclusion in Twelve European Countries. Journal of European Social Policy 12 (3): 211-225, https://doi.org/10.1177/0952872002012003394.

Van Tilburg, T. G. 1998. Losing and Gaining in Old Age: Changes in Personal Network Size and Social Support in a Four-Year Longitudinal Study. Journal of Gerontology 53 (6): S313-S323, https://doi.org/10.1093/geronb/53B.6.S313.

Van Tilburg, T. G., M. J. Aartsen, S. Van Der Pas. 2015. Loneliness after Divorce: A Cohort Comparison among Dutch Young-Old Adults. European Sociological Review 31 (3): 243-252, https://doi.org/10.1093/esr/jcu086.

Van Regenmortel, S., L. De Donder, A. S. Smetcoren, D. Lambotte, N. De Witte, D. Verté. 2018. Accumulation of Disadvantages: Prevalence and Categories of Old-Age Social Exclusion in Belgium. Social Indicators Research 140 (3): 1173-1194, http://dx.doi. org/10.1007/S11205-017-1817-8.

Van Regenmortel, S., B. Winter, A. Thelin, V. Burholt, L. De Donder. 2021. Exclusion from Social Relations Among Older People in Rural Britain and Belgium: A Cross-National Exploration Taking a Life-Course and Multilevel Perspective. Pp. 83-98 in Walsh, K., T. Scharf, S. Van Regenmortel, A. Wanka (eds.). Social Exclusion in Later Life, http://dx.doi. org/10.1007/978-3-030-51406-8_7.

Victor, C. R., A. Bowling. 2012. A Longitudinal Analysis of Loneliness among Older People in Great Britain. The Journal of Psychology 146 (3): 313-331, https://doi.org/10.1080/002 23980.2011 .609572$.

Viruell-Fuentes, E. A., P. Y. Miranda, S. Abdulrahim. 2012. More Than Culture: Structural Racism, Intersectionality Theory, and Immigrant Health. Social Science \& Medicine 75 (12): 2099-2106, https://doi.org/10.1016/j.socscimed.2011.12.037. 


\section{NV STATI / ARTICLES}

Walsh, K., E. O'Shea, T. Scharf. 2019. Rural Old-Age Social Exclusion: A Conceptual Framework on Mediators of Exclusion across the Life Course. Ageing \& Society 40 (11): 2311-2337, https://doi.org/10.1017/S0144686X19000606.

Walsh, K., T. Scharf, N. Keating. 2017. Social Exclusion of Older Persons: A Scoping Review and Conceptual Framework. European Journal of Ageing 14 (1): 81-98, https://doi. org/10.1007/s10433-018-0483-2.

Wenger, G. C. 1991. A Network Typology: From Theory to Practice. Journal of Aging Studies 5 (2): 147-162, https://doi.org/10.1016/0890-4065(91)90003-B.

Wenger, G. C., R. Davies, S. Shahtahmasebi, A. Scott. 1996. Social Isolation and Loneliness in Old Age: Review and Model Refinement. Ageing \& Society 16 (3): 333-358, https:// doi.org/10.1017/S0144686X00003457.

Yang, K., C. Victor. 2011. Age and Loneliness in 25 European Nations. Ageing \& Society 31 (8): 1368-1388, https://doi.org/10.1017/S0144686X1000139X.

(c) BY-NC Marja Aartsen, Kieran Walsh, Feliciano Villar, Ariela Lowenstein, Ruth Katz, Sigal Pearl Naim, Andreas Motel-Klingebiel, Anna Wanka, Anna Urbaniak, Thomas Hansen, Lucie Vidovićová, 2021.

(c) BY-NC Institute of Sociology of the Czech Academy of Sciences, 2021.

Marja Aartsen, PhD, currently works as s research professor at NOVA Norwegian Social research at Oslo Metropolitan University. She is a sociologist by training and specialised in longitudinal research on social exclusion, social inequalities, loneliness, and cognitive functioning in older adults. Contact e-mail: maraar@oslomet.no.

Kieran Walsh is Professor of Ageing and Public Policy and Director of the Irish Centre for Social Gerontology at National University of Ireland Galway. His research interests include social exclusion in later life, place and life-course transitions, and informal and formal infrastructures of care. Contact e-mail: kieran.walsh@nuigalway.ie.

Feliciano Villar, PhD, is a full professor at the Cognition, Developmental, and Educational Psychology Department of the University of Barcelona. His research focuses on generativity in later life and the participation and contributions of older people in families and communities. Contact e-mail: fvillar@ub.edu.

Prof. Emerita Ariela Lowenstein is a member of the Faculty of Welfare \& Health Sciences, Haifa University, Israel. She established the Graduate Department of Gerontology and the Centre for Research \& Study of Aging. Her research interests are intergenerational family relations, elder abuse and neglect, family caregiving, and gerontological education. Contact e-mail: ariela@research.haifa.ac.il.

Prof. Emerita Ruth Katz, a family sociologist, is a faculty member of the Sociology Department and the School of Social Work. She was for several years the head of the Department of Human Services and a senior researcher at the Center for Research \& Study 
of Aging, all at the University of Haifa, Israel. Her research interests are on intergenerational family relations, family caregiving, family lifestyles, family-work conflict and balance, successful ageing, and older adults' quality of life. Contact e-mail: ruth@soc.haifa.ac.il.

Sigal Naim, PhD, is a gerontologist, a lecturer at the Departments of Human Services, Yezreel Academic College, Israel, and an academic consultant for the programme of Gerontological Advisory and Treatment Management at the Academic Center for Law and Science, Israel. She also coordinates the Center for Research and Study of Aging at the University of Haifa, Israel. Her PhD thesis topic was on older adults' social media activity (mainly Facebook) - motivations, patterns of use, benefits and risks - and her post-doc dealt with digital literacy in old age. Contact e-mail: sigaln@yvc.ac.il.

Andreas Motel-Klingebiel, Dr. phil., Sociologist and Gerontologist, is Professor in Ageing and Later Life and Head of the Division Ageing and Social Change, Department of Culture and Society, Linköping University, Sweden. His research focuses on the connections between key societal processes, life-course trajectories, human ageing, and later life. His main thematic interests are quality of life, diversity, distributions, social inequality and exclusion, the life course and individual development, and social and cultural change. Contact e-mail: andreas.motel-klingebiel@liu.se.

Anna Wanka, PhD, is a sociologist and postdoctoral researcher at Goethe University in Frankfurt am Main and at the University of Stuttgart in Germany. She is interested in the social construction of age. Her areas of expertise comprise life-course transitions, the reproduction of social inequalities across the life course and material gerontology. Contact e-mail: wanka@em.uni-frankfurt.de.

Anna Urbaniak, PhD, is a sociologist who works on social exclusion in older age. She is a post-doctoral researcher at the University of Vienna and Jagiellonian University and a research associate at the Irish Centre for Social Gerontology. Her interest focusses on spatial aspects of ageing, life-course transitions, the re/production of social inequalities across the life course, ageing migrants, and people living with dementia. Contact e-mail: anna.urbaniak@univie.ac.at.

Thomas Hansen, PhD, works as a research professor at the Norwegian Institute of Public Health and at Norwegian Social Research (NOVA) at Oslo Metropolitan University.

A psychologist by training, his research focuses on subjective well-being, mental health, loneliness, social isolation, and volunteering in relation to ageing and later life. Contact e-mail: thomas.hansen@oslomet.no.

Lucie Vidovićová, PhD, is a sociologist. She is a co-founder of CERA - the Centre for Research on Ageing, a working group of the Department of Sociology at the Faculty of Social Studies, Masaryk University. Her research interests include age, ageing, and social roles, and modern technology in ageing societies. Contact e-mail: vidovicova@fss.muni.cz. 